\title{
Fibrous Dysplasia of Ethmoid: A Case report
}

\author{
S Alqahtani ${ }^{1 *}$, S Albahkaly ${ }^{2}$ and Omar Alhuzaim ${ }^{3}$ \\ ${ }^{1}$ Medical Student, King Saud bin Abdulaziz University for Health Sciences, Saudi Arabia \\ ${ }^{2}$ Otorhinolaryngology Consultant, NGHA, Saudi Arabia \\ ${ }^{3}$ Otorhinolaryngology Resident, NGHA, Saudi Arabia
}

Submission: June 05, 2018; Published: June 14, 2018

*Corresponding author: S Alqahtani, Medical Student, King Saud bin Abdulaziz University for Health Sciences, Saudi Arabia,

Email: s.alqahtani90@hotmail.com

\begin{abstract}
Objective: We report an extremely rare of fibrous dysplasia of ethmoid sinuses with loss of vision.

Method: Case reports and a review of the world literature concerning fibrous dysplasia of ethmoid sinuses.

Results: Fibrous dysplasia is a very rare disorder which represents a significant threat to vision and can also result in significant morbidity. There is a very high rate of recurrence in patients who do not receive appropriate treatment.
\end{abstract}

Conclusion: Therapeutic optic nerve decompression should be indicated whenever there is optic neuropathy nevertheless, who don't exhibit symptoms of optic neuropathy can be stable over time.

Keywords: Fibrous Dysplasia; Ethmoid Sinus, Optic Nerve; Fibrous Tissue; Paranasal Sinuses; Opacification; Mc Cune-Albright Syndrome; Bilateral Optic Disc Swelling; Hyperthyroidism; Growth Hormone

\section{Introduction}

Fibrous Dysplasia (FD) is a congenital, non-hereditary skeletal disorder that occurs with equal frequency in males and females. However, it's a developmental anomaly of bone formation in which the marrow is replaced by fibrous tissue [1]. The disease usually begins in the childhood and progresses throughout puberty and adolescence then becomes dormant in early adult life. About $75 \%$ of the cases are found under the age of 30 years. The long bone is the most common site of involvement, and the craniofacial bone comes next [2]. However, fibrous dysplasia of paranasal sinuses is rarely reported and often presents a diagnostic challenge [3].

\section{Case report}

A 17 years old Saudi girl with a known case of FD which presented with a history of severe frontal headache for weeks and associated with dizziness. CT scan of paranasal sinuses was done and showed that almost total opacification of the nasal cavity, thickened septum and opacification of the frontal sinuses mainly right side. Middle cranial fossa showed ground glass opacity of the clivus and sphenoid bone as well as the nasal septum. The impression that was taken is FD. One month later, the patient presented to the ER with acute loss of vision on the right eye as well as syncope that lasted for 15-20 minutes. Following that she regained her consciousness completely as well as her vision on the right eye. A CT scan of paranasal sinuses was repeated and showed FD of anterior skull base including the sphenoid and ethmoid sinuses with narrowing of optic nerve canals bilaterally. From there, the patient was referred to the ENT service for further workup (Figure 1).

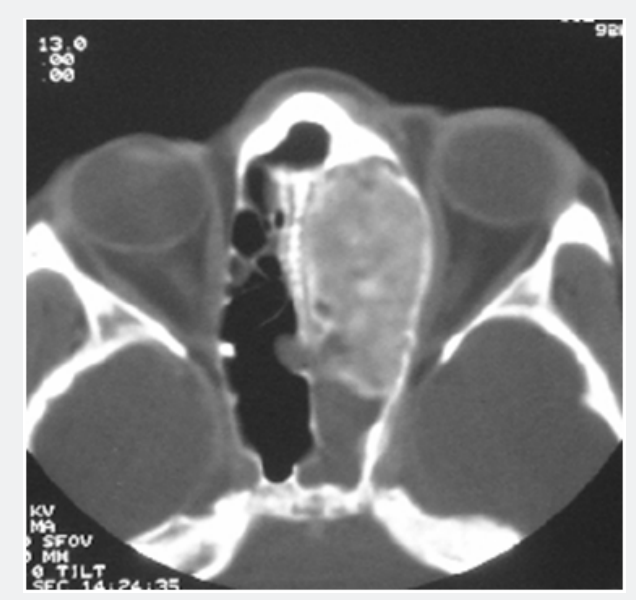

Figure 1: Axial CT scan showing the ground glass appearance of the fibrous dysplasia.

MRI was performed, which showed a clinical finding consistent with FD with expansion of the base of the skull 
causing encasement of the internal carotid arteries and the optic nerves. A biopsy was taken from the nasal septum and it was consistent with same diagnosis. The patient was further referred to the ophthalmology. Evaluation was performed and showed good visual acuity, but with significant visual field

defect on the right eye consistent with tunnel vision. On fundoscopy, bilateral optic disc swelling was noticed. A growth hormone level was within normal range. A right front temporal craniotomy and decompression of the optic canal and superior orbital fissure was done for her. Then, the patient was doing well for one year subsequent to the surgery. One-year post-operative, the patient experienced again the attack of headache, syncope and visual deterioration with a CT scan showing narrowing, encasement, of optic canal bilaterally with positive FD. This could be due to re-growth or incomplete decompression of optic nerve.

\section{Discussion}

An idiopathic and benign pathologic condition of the bone in which fibrous tissues gradually expand and replace the normal bone. It was first described by Albright in 1937. It results from post zygotic activating mutation in the signaling protein Gs alpha. It may appear as a condition of the skeleton only or as a part of the McCune-Albright syndrome (MAS), which is clinically defined as FD. In combination with either café au lait skin pigmentation and / or at least one of a number of hyper functioning endocrinopathies, including precocious puberty, hyperthyroidism and growth hormone (GH) excess [4]. Here, we will present a case of FD of anterior skull base including the sphenoid and ethmoid sinuses with narrowing of optic nerve canals bilaterally causing visual deterioration in young aged woman (Figure 2).

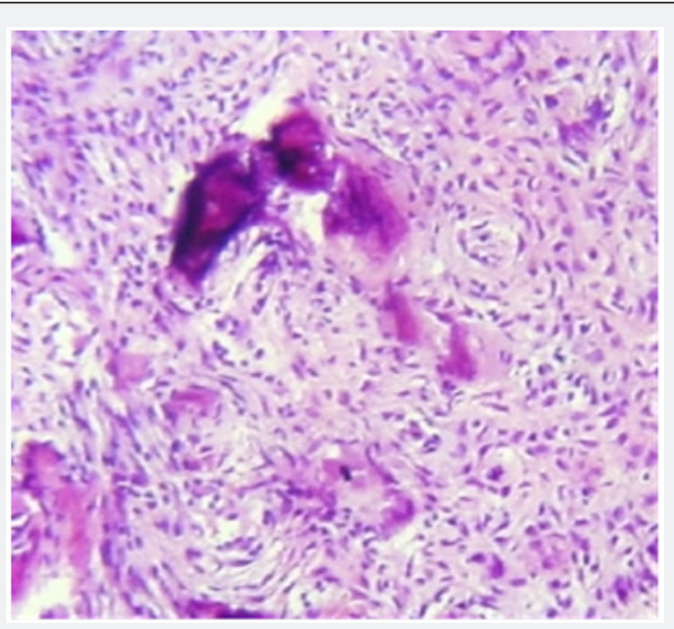

Figure 2: Histopathological specimen showing irregular trabeculae of woven bone intermixed with a connective tissue stroma.

Fibrous dysplasia has monostatic and polystotic forms, depending on whether one or more bones are affected, which are noted in $30 \%$ and $70 \%$ of patients, respectively. Malignant transformation is rare and is usually seen only in polystotic cases. Following the ribs and long bones, craniofacial bones are the second most common site of involvement and comprise $25 \%$ of the cases. Among FD of the head and neck, the maxilla and mandible are the most frequent sites to be involved, followed by the frontal, parietal and occipital bones. However, FD of the paranasal sinuses is very rare. It is usually secondary to the extension of the disease from adjacent bones. Most commonly, FD is asymptomatic until there is encroachment upon adjacent vital structures. Atypical pain in the head and face as well as sinusitis symptoms are most frequent observed clinical findings [5]. The "ground glass» bone appearance on C-T scans with bone window is the most useful radiographic sign for the diagnosis of FD. Treatment is aimed at correcting or preventing functional problems and achieving normal facial aesthetics [6].

Findings at the 1-year follow up after the FD was initially diagnosed in our patient with visual deterioration, confirmed that watch-and-wait is not acceptable in cases of FD complicated by progressive optic neuropathy. Because of that, early optic nerve decompression is highly recommended to preserve visual function in patients with craniofacial FD causing visual disturbance [7], as the decompression of the cystic area and additional soft bone involvement can restore visual acuity [8]. The extent of disease, patient's symptoms and the degree of cosmetic deformity will determine the extent of surgery [9]. There is association between growth hormone and FD that growth hormone excess, as part of McCune Albright Syndrome, represented a statistically significant risk factor for the development of optic neuropathy, because it promotes growth and expansion of FD. The growth hormone is treatable early in its course. Yet, it is important to catch it early to prevent further increase in the hormone and because of the absence of growth hormone excess, the optic neuropathy is quite low, and with such a low rate, the prophylactic decompression for the optic nerve has a low injury risk [10]. In our case, the growth hormone was within normal level.

\section{References}

1. Kavitha Vadde, David E (2000) Joint program in nuclear medicine. Fibrous Dysplasia.

2. Tehranzadeh J, Fung Y, Donohue M, Anavim A, Pribram HW (1998) Computed tomography of Paget disease of the skull versus fibrous dysplasia. Skeletal Radiol 27(12): 664-672.

3. Feldman, Rao VM, Lowry LD, Kelly LD (1986) Fibrous dysplasia of the paranasal sinuses. Otolaryng Head Neck 95(2): 222-224.

4. Cutler CM, Lee JS, Butman JA, FitzGibbon EJ, Kelly MH, et al. (2006) Long-term outcome of optic nerve encasement and optic nerve decompression in patients with Fibrous Dysplasia: risk factors for blindness and safety of observation. Neurosurgery 59(5): 1011-1017.

5. Yenigun A, Akyuz S (2015) Isolated fibrous dysplasia of the ethmoid sinus. SAGE Open Med Case Rep 3: 2050313X14568132.

6. Tung-Lung Tsai, Ching-Yin Ho, Yuan-Ching Guo, Winby Chen, ChingZong Lin (2003) Fibrous Dysplasia of ethmoid sinus. J Chin Med Assoc 66(2):131-133. 
7. Chen YR, Breidahi A, Chang CN (1997) Optic nerve decompression in fibrous dysplasia: indications, efficacy and safety. Plast Reconstr Surg 99(1): 22-30.

8. Kurimoto M, Endo S, Onizuka K, Akai T, Takaku A (1996) Extradural optic nerve decompression for fibrous dysplasia with a favorable visual outcome. Neurol Med Chir (Tokyo) 36(2): 102-105.
9. Ferguson BJ (1994) Fibrous dysplasia of the paranasal sinuses. Am J Otolaryngol 15(3): 227-230.

10. Sunday O, Marilyn H, Beth B, Natasha C, et al. (2006) Pegvisomant for the Treatment of gsp-Mediated Growth Hormone excess in patients with McCune Albright Syndrome. The Journal of Clinical Endocrinology \& Metabolism 91(8): 2960-2966.

\section{Your next submission with Juniper Publishers will reach you the below assets}

- Quality Editorial service

- Swift Peer Review

- Reprints availability

- E-prints Service

- Manuscript Podcast for convenient understanding

- Global attainment for your research

- Manuscript accessibility in different formats ( Pdf, E-pub, Full Text, Audio)

- Unceasing customer service

Track the below URL for one-step submission https://juniperpublishers.com/online-submission.php 